EISSN 2667-4440
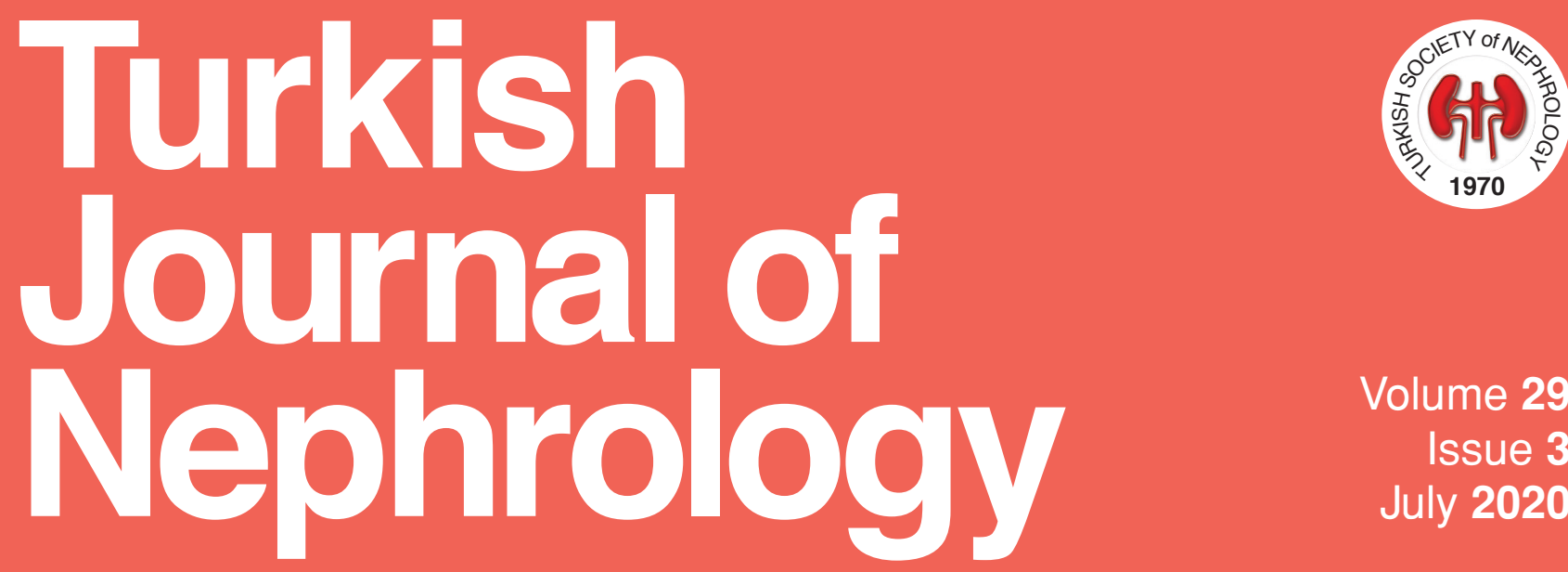

Volume 29

Issue 3 July 2020

\begin{tabular}{l}
\hline Page 185 \\
Acute Kidney \\
Injury in SARS- \\
CoV-2 Infected \\
Critically III \\
Patients
\end{tabular}

\title{
Page 205
}

The Effect

of Ultrapure

Dialysate on

Clinical Outcomes

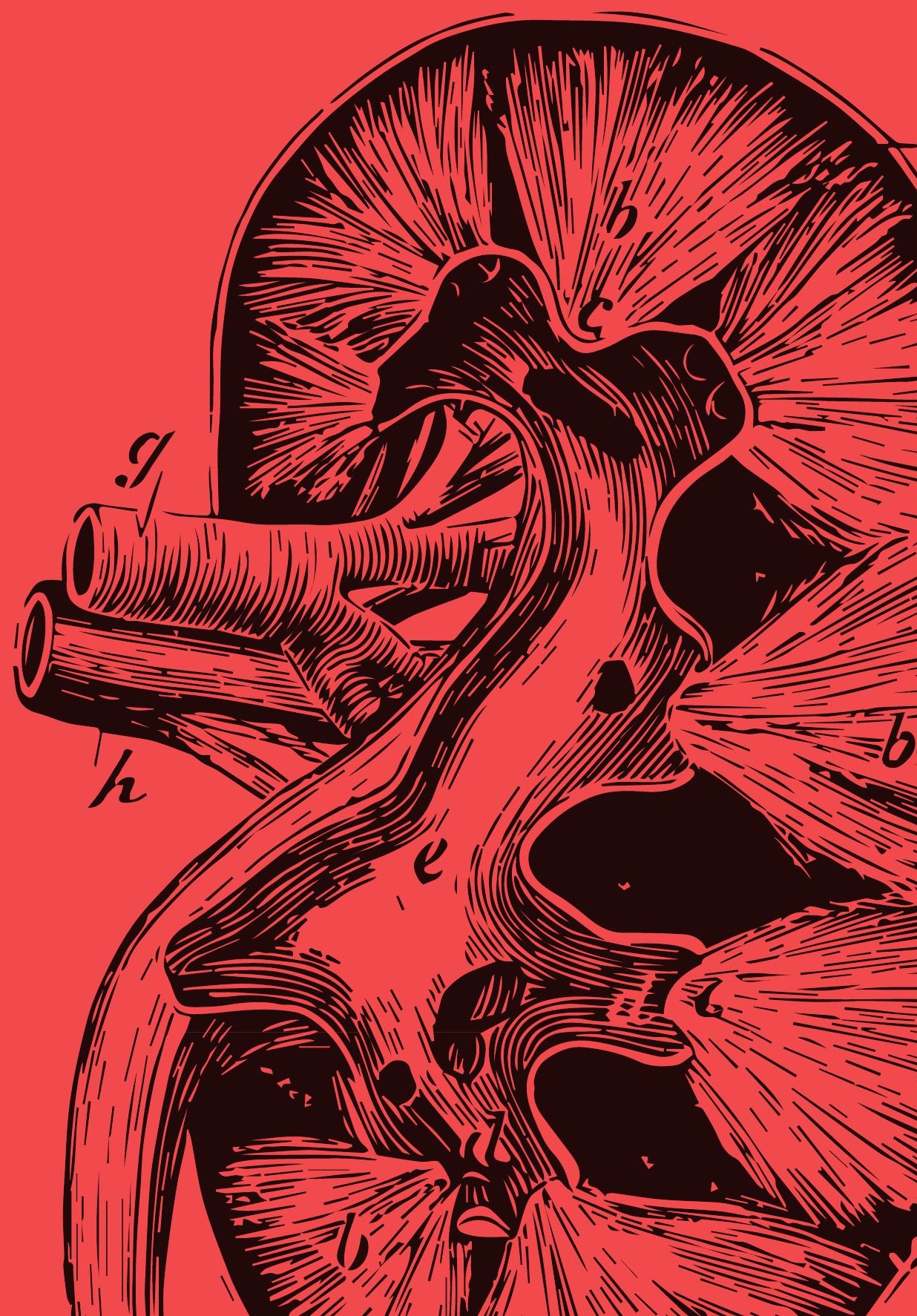




\section{Turkish \\ Journal of \\ Nephrology}

Editor in Chief

Bülent Tokgöz

Division of Nephrology, Erciyes University

School of Medicine, Kayseri, Turkey

\section{Editors}

Sedat Üstündağ

Division of Nephrology, Trakya University

School of Medicine, Edirne, Turkey

\section{Zeki Tonbul}

Division of Nephrology, Necmettin Erbakan

University School of Medicine,

Konya, Turkey

Mehmet Koç

Division of Nephrology, Marmara University

School of Medicine, Istanbul, Turkey

\section{Savaş Öztürk}

Division of Nephrology, Haseki Training and

Research Hospital, İstanbul, Turkey

Ferruh Artunç

Division of Nephrology, Tuebingen University,

Tuebingen, Germany

\section{Aydın Ünal}

Division of Nephrology, Medipol University

School of Medicine, İstanbul, Turkey

\section{Ali Düzova}

Division of Pediatric Nephrology, Hacettepe University, School of Medicine, Ankara, Turkey

\section{Previous Editors in Chief Ekrem Erek}

Istanbul University Cerrahpaşa School of

Medicine, İstanbul, Turkey

\section{Emel Akoğlu}

Marmara University School of Medicine, İstanbul, Turkey

\section{Cengiz Utaş}

Erciyes University School of Medicine, Kayseri, Turkey

\section{Bülent Altun}

Hacettepe University School of Medicine, Ankara, Turkey

\section{Bioistatistics Editor}

Gökmen Zararsız

Division of Biostatistics and Informatics, Erciyes

University School of Medicine, Kayseri

\section{Editorial Board}

Bülent Altun

Division of Nephrology, Hacettepe University

School of Medicine, Ankara, Turkey

\section{Mustafa Arıcı}

Division of Nephrology, Hacettepe University School of Medicine, Ankara, Turkey

\section{Turgay Arınsoy}

Division of Nephrology, Gazi University

School of Medicine, Ankara, Turkey

\section{Kenan Ates}

Division of Nephrology, Ankara University

School of Medicine, Ankara, Turkey

\section{Jonas Axelsson}

Division of Clinical Immunology, Karolinsk University Hospital, Stockholm, Sweden

\section{Peter Barany}

Division of Clinical Science, Intervention and Technology, Stockholm Sweden

\section{Vecihi Batuman}

Division of Nephrology, Tulane Univeristy School of Medicine, Los Angeles, USA

\section{Juan Jesus Carrero}

Department of Medical Epidemiology and

Biostatistics, Karolinska Institute, Solna,

Sweden

\section{Taner Çamsarı}

Division of Nephrology, Dokuz Eylü University School of Medicine, İmir, Turkey

\section{Ülver Derici}

Division of Nephrology, Gazi University School of Medicine, Ankara, Turkey

\section{Soner Duman}

Division of Nephrology, Ege University School of Medicine, izmir, Turkey

\section{Ethics Editor}

\section{Berna Arda}

Division of History of Medicine and Medical Ethics, Ankara University School of Medicine, Ankara,

Turkey

\section{Tevfik Ecder}

Division of Nephrology, Istanbul Bilim University School of Medicine, İstanbul, Turkey

\section{Fevzi Ersoy}

Division of Nephrology, Akdeniz University

School of Medicine, Antalya, Turkey

Talat Alp ìkizler

Division of Nephrology, Department of Medicine, Vanderbilt University Medical Center, Nashville, Tennessee, USA

\section{Rümeyza Kazancıoğlu}

Division of Nephrology, Bezmialem University

School of Medicine, İstanbul, Turkey

\section{Norbert Lameire}

Division of Nephrology, Ghent University School of Medicine and Health Sciences, Ghent, Belgium

\section{Bengt Lindholm}

Department of Clinical Sciences, Intervention and Technology (CLINTEC), Karolinska Institute Solna, Sweden

\section{Francesca Mallamaci}

Division of Nephrology, Hypertension and Renal Transplantation, Ospedali Riuniti, Reggio Cal, Italy

\section{Ercan Ok}

Division of Nephrology, Ege University School of Medicine, Izmir, Turkey

\section{Alberto Ortiz}

Division of Nephrology, University Autonoma of Madrid, Madrid, Spain

Nurhan Seyahi

Division of Nephrology, Istanbul University Cerrahpașa School of Medicine, İstanbul, Turkey

\section{Kamil Serdengeçti}

Emeritus Professor, Division of Nephrology, Istanbul University Cerrahpașa School of Medicine, Istanbul, Turkey

\section{Siren Sezer}

Division of Nephrology, Atılım University School of Medicine, Ankara, Turkey

\section{Gültekin Süleymanlar}

Division of Nephrology, Akdeniz University School of Medicine, Antalya, Turkey

\section{Peter Stenvinkel}

Division of Renal Medicine, Karolinska Institutet, Solna, Sweden

\section{Hüseyin Töz}

Division of Nephrology, Ege University

School of Medicine, Ankara, Turkey

\section{Serhan Tuğlular}

Division of Nephrology, Marmara University School of Medicine, İstanbul, Turkey

\section{Aydın Türkmen}

Division of Nephrology, İstanbul University School of Medicine, İstanbul, Turkey

\section{Raymond Vanholder}

Division of Nephrology, University Hospital Ghent, Ghent, Belgium

\section{Abdulgaffar Vural}

Emeritus Professor, Gülhane Military Academy School of Medicine, Ankara, Turkey

\section{Alaattin Yıldız}

Division of Nephrology, İstanbul University School of Medicine, İstanbul, Turkey

\section{Carmine Zoccali}

Nephrology, Dialysis and Transplantation Unit, Ospedali Riuniti, Reggio Calabria, Italy

\section{AVES \\ Publisher \\ Ibrahim KARA}

Publication Director Ali ŞAHIN

Editorial Development Gizem KAYAN TEKAÜT

Deputy Publication Director Gökhan ÇiMEN
Publication Coordinators

İrem SOYSAL

ArzU YILDIRIM

Deniz KAYA

Gülnur MERCAN

Bahar ALBAYRAK

Finance and Administration Zeynep YAKIŞIRER ÜREN Betül ÇiMEN
Project Coordinators

Sinem Fehime KOZ

Doğan ORUÇ

Graphics Department

Ünal ÖZER

Deniz Elif DURAN

Beyzanur KARABULUT
Contact

Address: Büyükdere Cad.

105/9 34394 Mecidiyeköy,

Şişli, i̇stanbul, Turkey

Phone: +90 2122171700

Fax: +90 2122172292

E-mail: info@avesyayincilik.com 


\section{Turkish \\ Journal of \\ Nephrology}

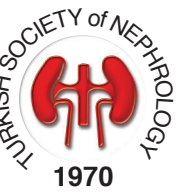

\section{Aims and Scope}

Turkish Journal of Nephrology (Turk J Nephrol) is a doubleblind peer-reviewed, open access, an international online-only publication of the Turkish Society of Nephrology. The journal is a quarterly publication, published in January, April, July and October. The publication language of the journal is English.

Turkish Journal of Nephrology aims to contribute to the literature by publishing manuscripts at the highest scientific level in the fields of nephrology, dialysis and transplantation. The journal publishes original articles, rare case reports, reviews, and letters to the editor that are prepared in accordance with the ethical guidelines.

The scope of the journal includes but not limited to; remarkable clinical and experimental investigations conducted in all fields of nephrology. The target audience of the journal includes specialists and professionals working and interested in all disciplines of nephrology and kidney care.

The editorial and publication processes of the journal are shaped in accordance with the guidelines of the International Committee of Medical Journal Editors (ICMJE), World Association of Medical Editors (WAME), Council of Science Editors (CSE), Committee on Publication Ethics (COPE), European Association of Science Editors (EASE), and National Information Standards Organization (NISO). The journal is in conformity with the Principles of Transparency and Best Practice in Scholarly Publishing (doaj.org/bestpractice).

Turkish Journal of Nephrology is currently indexed in Web of Science-Emerging Sources Citation Index, Scopus, EBSCO, and TUBITAK ULAKBIM TR Index.

Processing and publication are free of charge with the journal. No fees are requested from the authors at any point throughout the evaluation and publication process. All manuscripts must be submitted via the online submission system, which is available at www.turkjnephrol.org.
The journal guidelines, technical information, and the required forms are available on the journal's web page.

All expenses of the journal are covered by the Turkish Society of Nephrology. Potential advertisers should contact the Editorial Office. Advertisement images are published only upon the Editor-inChief's approval.

Statements or opinions expressed in the manuscripts published in the journal reflect the views of the author(s) and not the opinions of the Turkish Society of Nephrology, editors, editorial board, and/or publisher; the editors, editorial board, and publisher disclaim any responsibility or liability for such materials.

Turkish Journal of Nephrology is an open-access publication and the journal's publication model is based on the Budapest Open Access Initiative (BOAI) declaration. Journal's archive is available online, free of charge at www.turkjnephrol.org. Turkish Journal of Nephrology's content is licensed under a Creative Commons Attribution 4.0 International License.

Editor in Chief: Bülent Tokgöz

Address: Deparment of Nephrology, Erciyes University School of Medicine, 38039 Kayseri, Turkey

Phone: +902122194882

Fax: +90 2122194882

E-mail: bulentto@gmail.com

Publisher: AVES

Address: Büyükdere Cad. 105/9 34394 Mecidiyeköy, Şişli, İstanbul, Turkey

Phone: +902122171700

Fax: +90 2122172292

E-mail: info@avesyayincilik.com

Web page: avesyayincilik.com 


\section{Turkish \\ Journal of \\ Nephrology}

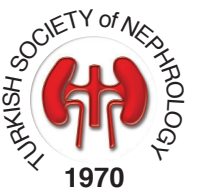

\section{Instruction to Authors}

Turkish Journal of Nephrology (Turk J Nephrol) is the double-blind peer reviewed, open access, international online-only publication of Turkish Society of Nephrology. The journal is a quarterly publication, published in January, April, July and October. The publication language of the journal is English.

Turkish Journal of Nephrology aims to contribute to the literature by publishing manuscripts at the highest scientific level in the fields of nephrology, dialysis and transplantation. The journal publishes original articles, rare case reports, reviews, and letters to the editor that are prepared in accordance with the ethical guidelines.

The editorial and publication processes of the journal are shaped in accordance with the guidelines of the International Council of Medical Journal Editors (ICMJE), the World Association of Medical Editors (WAME), the Council of Science Editors (CSE), the Committee on Publication Ethics (COPE), the European Association of Science Editors (EASE), and National Information Standards Organization (NISO). The journal conforms to the Principles of Transparency and Best Practice in Scholarly Publishing (doaj.org/bestpractice).

Originality, high scientific quality, and citation potential are the most important criteria for a manuscript to be accepted for publication. Manuscripts submitted for evaluation should not have been previously presented or already published in an electronic or printed medium. The journal should be informed of manuscripts that have been submitted to another journal for evaluation and rejected for publication. The submission of previous reviewer reports will expedite the evaluation process. Manuscripts that have been presented in a meeting should be submitted with detailed information on the organization, including the name, date, and location of the organization.

Manuscripts submitted to Turkish Journal of Nephrology will go through a double-blind peer-review process. Each submission will be reviewed by at least two external, independent peer reviewers who are experts in their fields in order to ensure an unbiased evaluation process. The editorial board will invite an external and independent editor to manage the evaluation processes of manuscripts submitted by editors or by the editorial board members of the journal. The Editor in Chief is the final authority in the decision-making process for all submissions.

An approval of research protocols by the Ethics Committee in accordance with international agreements (World Medical Association Declaration of Helsinki “Ethical Principles for Medical Research
Involving Human Subjects," amended in October 2013, www.wma. net) is required for experimental, clinical, and drug studies and for some case reports. If required, ethics committee reports or an equivalent official document will be requested from the authors. For manuscripts concerning experimental research on humans, a statement should be included that shows that written informed consent of patients and volunteers was obtained following a detailed explanation of the procedures that they may undergo. For studies carried out on animals, the measures taken to prevent pain and suffering of the animals should be stated clearly. Information on patient consent, the name of the ethics committee, and the ethics committee approval number should also be stated in the Materials and Methods section of the manuscript. It is the authors' responsibility to carefully protect the patients' anonymity. For photographs that may reveal the identity of the patients, signed releases of the patient or of their legal representative should be enclosed and the publication approval must be provided in the Materials and Methods section.

All submissions are screened by a similarity detection software (iThenticate by CrossCheck).

In the event of alleged or suspected research misconduct, e.g., plagiarism, citation manipulation, and data falsification/fabrication, the Editorial Board will follow and act in accordance with COPE guidelines.

Each individual listed as an author should fulfill the authorship criteria recommended by the International Committee of Medical Journal Editors (ICMJE - www.icmje.org). The ICMJE recommends that authorship be based on the following 4 criteria:

1 Substantial contributions to the conception or design of the work; or the acquisition, analysis, or interpretation of data for the work; AND

2 Drafting the work or revising it critically for important intellectual content; AND

3 Final approval of the version to be published; AND

4 Agreement to be accountable for all aspects of the work in ensuring that questions related to the accuracy or integrity of any part of the work are appropriately investigated and resolved.

In addition to being accountable for the parts of the work he/she has done, an author should be able to identify which co-authors are 


\section{Turkish \\ Journal of \\ Nephrology}

responsible for specific other parts of the work. In addition, authors should have confidence in the integrity of the contributions of their co-authors.

All those designated as authors should meet all four criteria for authorship, and all who meet the four criteria should be identified as authors. Those who do not meet all four criteria should be acknowledged in the title page of the manuscript.

Turkish Journal of Nephrology requires corresponding authors to submit a signed and scanned version of the authorship contribution form (available for download through turkjnephrol.org) during the initial submission process in order to act appropriately on authorship rights and to prevent ghost or honorary authorship. If the editorial board suspects a case of "gift authorship," the submission will be rejected without further review. As part of the submission of the manuscript, the corresponding author should also send a short statement declaring that he/she accepts to undertake all the responsibility for authorship during the submission and review stages of the manuscript.

Turkish Journal of Nephrology requires and encourages the authors and the individuals involved in the evaluation process of submitted manuscripts to disclose any existing or potential conflicts of interests, including financial, consultant, and institutional, that might lead to potential bias or a conflict of interest. Any financial grants or other support received for a submitted study from individuals or institutions should be disclosed to the Editorial Board. To disclose a potential conflict of interest, the ICMJE Potential Conflict of Interest Disclosure Form should be filled in and submitted by all contributing authors. Cases of a potential conflict of interest of the editors, authors, or reviewers are resolved by the journal's Editorial Board within the scope of COPE and ICMJE guidelines.

The Editorial Board of the journal handles all appeal and complaint cases within the scope of COPE guidelines. In such cases, authors should get in direct contact with the editorial office regarding their appeals and complaints. When needed, an ombudsperson may be assigned to resolve cases that cannot be resolved internally. The Editor in Chief is the final authority in the decision-making process for all appeals and complaints.

Turkish Journal of Nephrology requires each submission to be accompanied by a Copyright License Agreement (available for download turkjnephrol.org). When using previously published content, including figures, tables, or any other material in both print and electronic formats, authors must obtain permission from the copyright holder. Legal, financial and criminal liabilities in this regard belong to the author(s). By signing the Copyright License Agreement, authors agree that the article, if accepted for publication by the Turkish Journal of Nephrology, will be licensed under a Creative Commons Attribution 4.0 International License (CC BY 4.0).

Statements or opinions expressed in the manuscripts published in Turkish Journal of Nephrology reflect the views of the author(s) and not the opinions of the editors, the editorial board, or the publisher; the editors, the editorial board, and the publisher disclaim any responsibility or liability for such materials. The final responsibility in regard to the published content rests with the authors.

\section{MANUSCRIPT PREPARATION}

The manuscripts should be prepared in accordance with ICMJE-Recommendations for the Conduct, Reporting, Editing, and Publication of Scholarly Work in Medical Journals (updated in December 2018 - http://www.icmje.org/icmje-recommendations.pdf). Authors are required to prepare manuscripts in accordance with the CONSORT guidelines for randomized research studies, STROBE guidelines for observational original research studies, STARD guidelines for studies on diagnostic accuracy, PRISMA guidelines for systematic reviews and meta-analysis, ARRIVE guidelines for experimental animal studies, and TREND guidelines for non-randomized public behavior.

Manuscripts can only be submitted through the journal's online manuscript submission and evaluation system, available at turkjnephrol.org. Manuscripts submitted via any other medium will not be evaluated.

Manuscripts submitted to the journal will first go through a technical evaluation process where the editorial office staff will ensure that the manuscript has been prepared and submitted in accordance with the journal's guidelines. Submissions that do not conform to the journal's guidelines will be returned to the submitting author with technical correction requests.

Authors are required to submit the following:

- Copyright Agreement Form,

- Author Contributions Form, and

- ICMJE Potential Conflict of Interest Disclosure Form (should be filled in by all contributing authors) during the initial submission. These forms are available for download at turkjnephrol.org). 


\section{Preparation of the Manuscript}

Title page: A separate title page should be submitted with all submissions and this page should include:

- The full title of the manuscript as well as a short title (running head) of no more than 50 characters,

- $\quad$ Name(s), affiliations, highest academic degree(s), and ORCID IDs of the author(s),

- Grant information and detailed information on the other sources of support,

- $\quad$ Name, address, telephone (including the mobile phone number) and fax numbers, and email address of the corresponding author,

- Acknowledgment of the individuals who contributed to the preparation of the manuscript but who do not fulfill the authorship criteria.

Abstract: An abstract should be submitted with all submissions except for Letters to the Editor. The abstract of Original Articles should be structured with subheadings (Objective, Materials and Methods, Results, and Conclusion). Please check Table 1 below for word count specifications.

Keywords: Each submission must be accompanied by a minimum of three to a maximum of six keywords for subject indexing at the end of the abstract. The keywords should be listed in full without abbreviations. The keywords should be selected from the National Library of Medicine, Medical Subject Headings database (https:// www.nlm.nih.gov/mesh/MBrowser.html).

Main Points: All submissions except letters to the editor should be accompanied by 3 to 5 "main points" which should emphasize the most noteworthy results of the study and underline the principle message that is addressed to the reader. This section should be structured as itemized to give a general overview of the article. Since "Main Points" targeting the experts and specialists of the field, each item should be written as plain and straightforward as possible.

\section{Manuscript Types}

Original Articles: This is the most important type of article since it provides new information based on original research. The main text of original articles should be structured with Introduction, Materials and Methods, Results, Discussion, and Conclusion subheadings. Please check Table 1 for the limitations for Original Articles.

Statistical analyses are essential features of medical studies, in order to answer the research questions with hypothesis testing. Statistical analyses must be conducted in accordance with international statistical reporting standards (Altman DG, Gore SM,
Gardner MJ, Pocock SJ. Statistical guidelines for contributors to medical journals. Br Med J 1983: 7; 1489-93). Information on statistical analyses should be provided with a separate subheading, as 'Statistical Analysis', under the Materials and Methods section. This section should detail the following:

(i) how the statistical assumptions are tested (e.g. Histogram and q-q plots were examined, Shapiro-Wilk's test was used to assess the data normality.);

(ii) which statistical methods are used for which purposes (e.g. To compare the miRNA levels of patients with and without CKD, a two-sided independent samples t test was applied.);

(ii) how the data values are expressed (e.g. Values are expressed as mean \pm SD or median(1st-3rd quartiles.);

(iv) which statistical software was used to analyze the data (e.g. Analyses were conducted using TURCOSA (Turcosa Analytics, Turkey) statistical software.).

Additionally, the study design (e.g. retrospective case-control, cross-sectional, cohort, etc.) and the sample size calculation procedure (power analysis) should also be detailed in the Materials and Methods section.

Units should be prepared in accordance with the International System of Units (SI).

Editorial Comments: Editorial comments aim to provide a brief critical commentary by reviewers with expertise or with high reputation in the topic of the research article published in the journal. Authors are selected and invited by the journal to provide such comments. Abstract, Keywords, and Tables, Figures, Images, and other media are not included.

Review Articles: Reviews prepared by authors who have extensive knowledge on a particular field and whose scientific background has been translated into a high volume of publications with a high citation potential are welcomed. These authors may even be invited by the journal. Reviews should describe, discuss, and evaluate the current level of knowledge of a topic in clinical practice and should guide future studies. The main text should contain Introduction, Clinical and Research Consequences, and Conclusion sections. Please check Table 1 for the limitations for Review Articles. 
Case Reports: There is limited space for case reports in the journal and reports on rare cases or conditions that constitute challenges in diagnosis and treatment, those offering new therapies or revealing knowledge not included in the literature, and interesting and educative case reports are accepted for publication. The text should include Introduction, Case Presentation, Discussion, and Conclusion subheadings. Please check Table 1 for the limitations for Case Reports.

Letters to the Editor: This type of manuscript discusses important parts, overlooked aspects, or lacking parts of a previously published article. Articles on subjects within the scope of the journal that might attract the readers' attention, particularly educative cases, may also be submitted in the form of a "Letter to the Editor." Readers can also present their comments on the published manuscripts in the form of a "Letter to the Editor." Abstract, Keywords, and Tables, Figures, Images, and other media should not be included. The text should be unstructured. The manuscript that is being commented on must be properly cited within this manuscript.

\section{Tables}

Tables should be included in the main document, presented after the reference list, and they should be numbered consecutively in the order they are referred to within the main text. A descriptive title must be placed above the tables. Abbreviations used in the tables should be defined below the tables by footnotes (even if they are defined within the main text). Tables should be created using the "insert table" command of the word processing software and they should be arranged clearly to provide easy reading. Data presented in the tables should not be a repetition of the data presented within the main text but should be supporting the main text.

\section{Figures and Figure Legends}

Figures, graphics, and photographs should be submitted as separate files (in TIFF or JPEG format) through the submission system. The files should not be embedded in a Word document or the main document. When there are figure subunits, the subunits should not be merged to form a single image. Each subunit should be submitted separately through the submission system. Images should not be labeled (a, b, c, etc.) to indicate figure subunits. Thick and thin arrows, arrowheads, stars, asterisks, and similar marks can be used on the images to support figure legends. Like the rest of the submission, the figures too should be blind. Any information within the images that may indicate an individual or institution should be blinded. The minimum resolution of each submitted figure should be $300 \mathrm{DPI}$. To prevent delays in the evaluation process, all submitted figures should be clear in resolution and large in size (minimum dimensions: $100 \times 100 \mathrm{~mm}$ ). Figure legends should be listed at the end of the main document.

All acronyms and abbreviations used in the manuscript should be defined at first use, both in the abstract and in the main text. The abbreviation should be provided in parentheses following the definition.

When a drug, product, hardware, or software program is mentioned within the main text, product information, including the name of the product, the producer of the product, and city and the country of the company (including the state if in USA), should be provided in parentheses in the following format: "Discovery St PET/CT scanner (General Electric, Milwaukee, WI, USA)"

All references, tables, and figures should be referred to within the main text, and they should be numbered consecutively in the order they are referred to within the main text.

Limitations, drawbacks, and the shortcomings of original articles should be mentioned in the Discussion section before the conclusion paragraph.

\section{References}

While citing publications, preference should be given to the latest, most up-to-date publications. If an ahead-of-print publication is cited, the DOI number should be provided. The authors are responsible for the accuracy of references. Journal titles should be

\begin{tabular}{|c|c|c|c|c|c|}
\hline Type of manuscript & Word limit & Abstract word limit & Reference limit & Table limit & Figure limit \\
\hline Original Article & 3500 & 250 (Structured) & 30 & 6 & 7 or total of 15 images \\
\hline Case Report & 1000 & 200 & 15 & No tables & 10 or total of 20 images \\
\hline Letter to the Editor & 500 & No abstract & 5 & No tables & No media \\
\hline
\end{tabular}




\section{Turkish \\ Journal of \\ Nephrology}

abbreviated in accordance with the journal abbreviations in Index Medicus/ MEDLINE/PubMed. When there are six or fewer authors, all authors should be listed. If there are seven or more authors, the first six authors should be listed followed by "et al." In the main text of the manuscript, references should be cited using Arabic numbers in parentheses. The reference styles for different types of publications are presented in the following examples.

Journal Article: Altun B, Soylemezoglu O, Tokgoz B, Yilmaz MI, Odabas AR, Koc M. Hemodialysis complications. Turk Neph Dial Transpl 2010; 70: 1-4.

Book Section: Sagawa K. Analysis of the CNS ischemic feedback regulation of the circulation. Reeve EB, Guyton AC (eds). Physical Basis of Circulation Transport. Philadelphia: WB Saunders, 1967; p.129-139.

Books with a Single Author: West JB. Respiratory Physiology. 2nd ed. Baltimore: Williams and Wilkins; 1974.

Editor(s) as Author: Huizing EH, de Groot JAM, editors. Functional reconstructive nasal surgery. Stuttgart-New York: Thieme; 2003.

Conference Proceedings: Bengisson S. Sothemin BG. Enforcement of data protection, privacy and security in medical informatics. In: Lun KC, Degoulet P, Piemme TE, Rienhoff O, editors. MEDINFO 92. Proceedings of the 7th World Congress on Medical Informatics; 1992 Sept 6-10; Geneva, Switzerland. Amsterdam: North-Holland; 1992. pp.1561-5.

Scientific or Technical Report: Cusick M, Chew EY, Hoogwerf B, Agrón E, Wu L, Lindley A, et al. Early Treatment Diabetic Retinopathy Study Research Group. Risk factors for renal replacement therapy in the Early Treatment Diabetic Retinopathy Study (ETDRS), Early Treatment Diabetic Retinopathy Study Kidney Int: 2004. Report No: 26.

Thesis: Yılmaz B. Ankara Üniversitesindeki Öğrencilerin Beslenme Durumları, Fiziksel Aktiviteleri ve Beden Kitle İndeksleri Kan Lipidleri Arasındaki Ilişkiler. H.Ü. Sağlık Bilimleri Enstitüsü, Doktora Tezi. 2007.

Manuscripts Accepted for Publication, Not Published Yet: Slots J. The microflora of black stain on human primary teeth. Scand J Dent Res. 1974.
Epub Ahead of Print Articles: Cai L, Yeh BM, Westphalen AC, Roberts JP, Wang ZJ. Adult living donor liver imaging. Diagn Interv Radiol. 2016 Feb 24. doi: 10.5152/dir.2016.15323. [Epub ahead of print].

Manuscripts Published in Electronic Format: Abood S. Quality improvement initiative in nursing homes: the ANA acts in an advisory role. Am J Nurs (serial online). 2002 Jun (cited 2002 Aug 12): 02(6). Available from: http://www.nursingworld.org/AJN/2002/june/ Wawatch.htm

\section{Revisions}

When submitting a revised version of a paper, the author must submit a detailed "Response to the reviewers" that states point by point how each issue raised by the reviewers has been covered and where it can be found (each reviewer's comment, followed by the author's reply and line numbers where the changes have been made) as well as an annotated copy of the main document. Revised manuscripts must be submitted within 30 days from the date of the decision letter. If the revised version of the manuscript is not submitted within the allocated time, the revision option may be canceled. If the submitting author(s) believe that additional time is required, they should request this extension before the initial 30-day period is over.

Accepted manuscripts are copy-edited for grammar, punctuation, and format. Once the publication process of a manuscript is completed, it is published online on the journal's webpage as an aheadof-print publication before it is included in its scheduled issue. A PDF proof of the accepted manuscript is sent to the corresponding author and their publication approval is requested within 2 days of their receipt of the proof.

Editor in Chief: Bülent Tokgöz

Address: Department of Nephrology, Erciyes University School of Medicine, 38039 Kayseri ,Turkey

Phone: +902122194882

Fax: +90 2122194882

E-mail:bulentto@gmail.com

Publisher: AVES

Address: Büyükdere Cad. 105/9 34394 Mecidiyeköy, Şişli, İstanbul, Turkey

Phone: +90 2122171700

Fax: +902122172292

E-mail: info@avesyayincilik.com

www.avesyayincilik.com 


\section{Turkish \\ Journal of \\ Nephrology}

\section{Contents}

\section{Original Articles}

Acute Kidney Injury in SARS-CoV-2 Infected Critically Ill Patients

Kürşat Gündoğan, Şahin Temel, Burcu Baran Ketencioğlu, Belal Rabah, Nuri Tutar, Murat Sungur

Comparison of GFR Values Measured with Different Methods and the Relative Renal Functions in Patients with Proven or Suspected Obstructive Uropathy

Fadime Demir, Tansel Ansal Balcı, Fikri Selçuk Şimşek, Mustafa Demir

Effects of Serum Calcium and Phosphorus on Anemia Development in Patients with Stage 3b and 4 Chronic

Kidney Disease

Koray Uludağ

The Effect of Ultrapure Dialysate on Clinical Outcomes and Mortality During One Year Follow-up in Patients

Undergoing Hemodialysis Treatment

Ibrahim Doğan, Nur Ünal Kaya, Hüseyin Kayadibi

Contraception and Child Birth in Kidney Transplant Patients: What Are We Missing as Physicians?

Emrah Günay, Cenk Gökalp

Prevalence and Characteristics of Atrial Fibrillation in Turkish Patients Undergoing Hemodialysis

Nuri Barış Hasbal, Yener Koç, Tamer Sakacı, Mustafa Sevinç, Zuhal Atan Uçar, Tuncay Şahutoğlu, Cüneyt Akgöl, Elbis Ahbap, Abdülkadir Ünsal,

Taner Baştürk

Evaluation of Cardiovascular Status with Non-Invasive Markers in Patients with Diabetic and Non-Diabetic Chronic

Kidney Disease

Süleyman Karaköse, ibrahim Güney

Clinical Course of Kidney Donors in the Long Term after Transplant: A Single-Center Experience

Kadir Gökhan Atılgan, Mehmet Deniz Aylı

\section{Review}

Molecular Targeted Cancer Therapies and the Kidney

Özge Baş Aksu, Rezzan Eren Sadioğlu, Şule Şengül

\section{Case Reports}

Renal Artery Stenosis Presenting with Resistant Hypertension in Children and Adolescents: A Report of Five Cases Mehtap Sak, İbrahim Gökçe, Neslihan Çiçek, Nurdan Yıldız, Feyyaz Baltacıoğlu, Harika Alpay

An Unusual Case of Acute Kidney Injury with AA Amyloidosis

Rezzan Eren Sadioğlu, Saba Kiremitçi, Sim Kutlay, Şule Şengül 